\section{O legado de Cabanis: hipótese sobre raízes da educação médica no Brasil}

\author{
The legacy of Cabanis: a hypothesis on the roots \\ of medical education in Brazil
}

\section{El legado de Cabanis: hipótesis sobre las raíces de la educación médica en Brasil}

Naomar Almeida-Filho 1

doi: 10.1590/0102-311X00206416

\section{Resumo}

Georges Cabanis foi um reformador da prática clínica e do ensino médico que, na Revolução Francesa, lançou as bases conceituais do modelo de educação implantado na França no decorrer do século XIX. Tal modelo, por sua vez, marcou a organização dos sistemas educacionais de muitos países latino-americanos. Este artigo tem como objetivo apresentar e justificar uma hipótese: o modelo de educação médica ainda hoje hegemônico no Brasil ainda hoje se baseia na reforma cabasiana, mantendo uma perspectiva conceitual linear e cartesiana, com matriz curricular disciplinar, formatos tradicionais de prática pedagógica e submissão à lógica profissional corporativa. Para melhor compreensão do contexto social e politico dos processos históricos geradores desse anacronismo, em primeiro lugar, apresento uma súmula da biografia e do conjunto pensamento-obra de Georges Cabanis, introduzindo-o como personagem central em seu contexto histórico. Em segundo lugar, destaco os principais elementos estruturais do modelo cabanisiano, com foco especial no ensino médico, tomando alguns dos seus textos autorais como fonte documental. Finalmente, em breves traços, apresento o projeto de reforma do ensino médico elaborado por Cabanis e seus colaboradores como subsídio para avaliação preliminar da hipótese proposta.

Educação em Saúde; Ensino; Universidades; História da Medicina

\section{Correspondência}

N. Almeida-Filho

Rua Waldemar Falcão 641, apto. 501, Salvador, BA 40295-010, Brasil.

naomaralmeida@gmail.com

1 Universidade Federal da Bahia, Salvador, Brasil. 


\section{Introdução}

Este é o terceiro artigo de uma série sobre a educação médica brasileira 1,2 . Para melhor entender a crise de formação de profissionais e de intelectuais que demarca a atual conjuntura nacional no campo da saúde, propõe-se apreciar raízes históricas e fundamentos conceituais dos modelos de ensino médico vigentes no mundo e no Brasil. Para isso, é recomendável reler os clássicos, com cuidado e profundidade.

Segundo Foucault 3 , no contexto da formação médica na França no final do século XVIII, predominam uma perspectiva doutrinária e uma pedagogia retórica, distanciadas dos avanços científicos e filosóficos do Iluminismo. No plano institucional, há excesso de escolas médicas de baixa qualidade, nas quais cátedras são negociadas pela nobreza decadente como fonte de renda para professores autorizados a ministrar cursos pagos. Fora das universidades, estudantes compram a preparação para seus exames, "o que torna os estudos médicos muito custosos, tanto mais que, para ter formação prática, o novo doutor deve seguir, em suas visitas, um médico renomado a quem é preciso indenizar" 3 (p. 48). Tal cenário de elitismo, pouca eficácia técnica, alto custo e baixa qualidade pedagógica do ensino médico na França setecentista parece corresponder, mais de um século depois, ao contexto norte-americano do fim do século XIX sintetizado no Relatório Flexner 4 que, em certa medida, persiste em várias partes do mundo, incluindo o Brasil neste início do século XXI 5.

Para Foucault 3, a pauta política da Revolução Francesa inicialmente incluía medidas radicais como extinção de confrarias e corporações e fechamento de universidades e academias, complementadas por três estratégias de longo prazo: primeiro, regulamentação rigorosa, condicionando o exercício da profissão médica a uma instrução superior credenciada pelo Estado; segundo, reorganização da estrutura de serviços assistenciais; terceiro, revisão profunda do próprio sistema de ensino. Em 1792, o médico e farmacêutico Antoine-François de Fourcroy (1755-1809) propôs a recriação do sistema francês de educação mediante o "ensino livre das ciências e das artes" e de reestruturação da formação em saúde pautada em uma "medicina em liberdade". O marco fundamental dessa proposta compreendia a unificação entre medicina, cirurgia e farmacoquímica, retificando clivagem histórica vigente desde a Idade Média. Rejeitando a formação médica de base retórica, Fourcroy cria uma école de santé em Paris, com cursos integrados de medicina, farmácia, higiene e administração pública para formação de um perfil profissional mais aberto e polivalente 3,6. Aprovada com entusiasmo pelos próceres da Revolução Francesa, a proposta logo se ampliaria para duas outras escolas em Montpellier e Estrasburgo, tradicionais centros de educação médica. Relata Foucault: "O povo será amplamente admitido na nova escola de saúde; (...) serão escolhidos em cada distrito alunos que tenham boa conduta, costumes puros, amor à República e ódio aos tiranos, cultura bem cuidada e, sobretudo, conhecimento de algumas ciências que servem de preliminar para a arte de curar. (...) Em vez de ser, como a antiga faculdade, o lugar de um saber esotérico e livresco, a nova escola de saúde [deve ensinar] em vez das vãs fisiologias, a verdadeira arte de curar" 3 (p. 76).

Essa proposta compreende acesso amplo de estudantes oriundos de classes populares à educação universitária anteriormente reservada às elites, visando à formação de profissionais de saúde em escolas próprias de saúde em vez de treinar especialistas em escolas de doença chamadas faculdades de medicina. Impressiona a pertinência e atualidade dessa pauta de reforma social em que, nos momentos iniciais da Revolução Francesa, despontavam movimentos de reestruturação do campo da saúde.

Infelizmente, ressalta Foucault 3 , a ordem política tinha outros planos. Os vetores da restauração iniciada pelo Diretório e posteriormente consolidada no Consulado de Bonaparte neutralizaram propostas revolucionárias orientadas à emancipação dos sujeitos. Em vez de uma prática clínica não só como "momento essencial da coerência científica, mas também da utilidade social e da pureza política da nova organização da medicina” 3 (p. 75), fomentava-se a recuperação institucional da medicina para "por fim à perigosa experiência da liberdade, um modo, no entanto, de lhe conceder sentido positivo, como também uma via para restaurar, conforme o desejo de alguns, as estruturas do Antigo Regime” 3 (p. 75). A reforma educacional encaminhada pelos jacobinos em 1792 terminou superada pela restauração das faculdades de medicina e direito, que ressurgiram ainda mais poderosas na era napoleônica, operando modelos de educação superior orgânicos à nova ideologia burguesa - materialista, individualista, produtivista e laica.

Um dos principais líderes intelectuais nesse contexto de restauração da tradição médica, ajustada à matriz cultural da nascente burguesia, é Pierre-Jean-Georges Cabanis. O modelo educacional concebido por ele e seus pares, adotado na reforma napoleônica da educação de 1806-1808, estabeleceu 
as bases do sistema de ensino superior e profissional implantado na França oitocentista, extrapolando o âmbito restrito da educação superior em saúde 7 e influenciando outros sistemas educacionais, especialmente na Europa meridional e nos países latino-americanos, como o Brasil do século XIX 8 .

O papel de Georges Cabanis como líder reformador da educação médica, sob bases científicas e diretrizes tecnológicas oriundas do pensamento cartesiano, tem sido em geral pouco reconhecido entre nós. As raras referências na literatura nacional à obra de Cabanis - suposto como defensor da inferioridade da mulher ${ }^{9}$, precursor do conceito de instinto sexual 10, por sua teoria fisiológica das ideias 11 e, curiosamente, valorizador da mestiçagem como fator de igualdade entre os homens, considerado nesse caso como um antagonista ao racismo de Gobineau 12 - não incluem sua contribuição ao ensino médico e à educação superior.

Este artigo tem por objetivo apresentar e justificar a seguinte hipótese: o modelo de educação médica hoje hegemônico no Brasil se organiza numa perspectiva ainda cabanisiana, definida por uma matriz disciplinar, com formatos tradicionais de estrutura curricular e prática pedagógica, submetida à lógica profissional corporativa. A apreciação dessa hipótese requer, sem dúvida, melhor compreensão do contexto social e político dos processos históricos geradores desse anacronismo. Nesse sentido, em primeiro lugar, apresenta-se uma súmula da biografia e do pensamento-obra de Georges Cabanis, introduzindo-o como personagem central num dado contexto histórico. Em segundo lugar, destacam-se os principais elementos estruturais do modelo cabanisiano, com foco especial no ensino médico, tomando alguns dos seus textos autorais como fonte documental. Finalmente, em breves traços, apresenta-se o projeto de reforma do ensino médico elaborado por Cabanis e seus colaboradores.

\section{Biografia breve de Cabanis}

Esta seção resume informações constantes em textos selecionados sobre vida e obra de Cabanis $13,14,15,16,17,18$.

Pierre-Jean-Georges Cabanis (1757-1808) foi um médico francês que, na virada do século XIX, alcançou grande reputação como filósofo e líder político. A Figura 1 mostra sua efígie.

\section{Figura 1}

Pierre-Jean-Georges Cabanis (litogravura de Ambroise Tardieu - circa 1790).

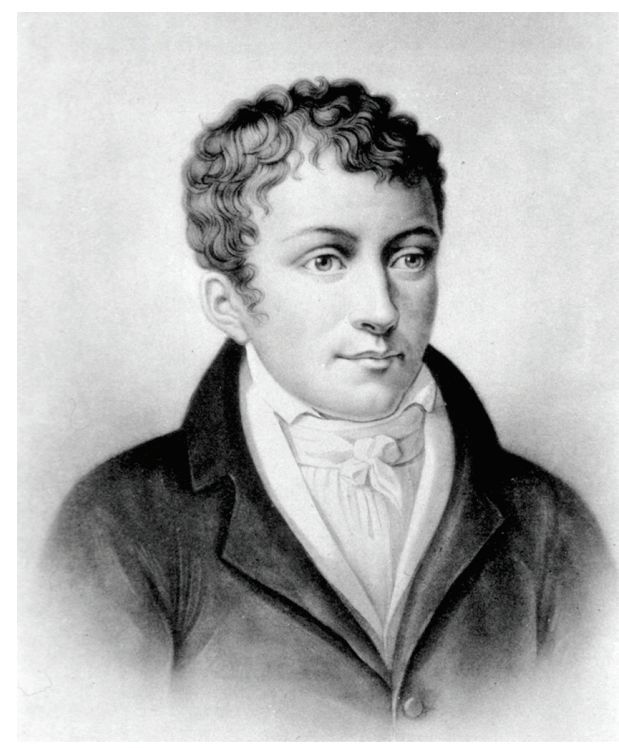


Cabanis nasceu em 5 de junho de 1757, em Cosnac. Órfão aos sete anos, o pequeno Cabanis é inicialmente educado na paróquia local. Aos dez anos, admitido no internato de Brive, logo alcança os limites da educação provincial. Com a proteção de Turgot, ministro do Rei Luís XVI, o jovem Cabanis é enviado a Paris em 1771 para completar seus estudos, revelando-se dedicado e brilhante estudioso dos clássicos, com talento inato para aprendizado de línguas. Em 1773, contratado como secretário particular do Príncipe Massalski, bispo polonês em visita à França, muda-se para Varsóvia (Polônia). De volta a Paris em 1775, dedica-se a estudos filosóficos e amplia seu horizonte de interesses para o campo das ciências naturais. Participa com entusiasmo dos famosos saraus do Círculo de Auteil, promovidos por Madame Helvétius, que o convida a residir na sua mansão, onde convive com grandes nomes do Iluminismo francês.

Nessa época, Cabanis torna-se amigo de personalidades que influenciarão toda sua vida, como Dominique-Joseph Garat, advogado que se tornaria um dos principais líderes políticos da Revolução Francesa, e o Marquês de Condorcet, filósofo e matemático interessado em educação (autor de Cinq Mémoires sur l'Instruction Publique, texto base para várias propostas de reforma da educação pública na era revolucionária). A conselho de Léon Dubreuil, médico clínico e fisiologista, começa estudos preparatórios em 1778, acompanhando seu mentor nas rondas no Hospital Charité. Em 1780, Cabanis é finalmente aceito na rigorosa Faculdade de Medicina de Paris. Em 1783, interrompe seus estudos para se tornar, por breve tempo, seguidor do famoso hipnotizador Franz Anton Mesmer.

Com a morte de Dubreuil, Cabanis retoma seus estudos na Faculdade de Medicina de Reims, graduando-se com louvor em 1784. No ano seguinte, abre uma clínica gratuita para os pobres de Auteuil e se dedica a pesquisas científicas sobretudo em fisiologia humana. Em 1788, escreve sua primeira obra sobre semiologia clínica, um opúsculo intitulado Du Degré de Certitude de la Médecine (publicado em 1797), em que explora as interfaces entre medicina e filosofia, criticando o uso indevido da matemática e sua incipiente teoria probabilística no processo de diagnóstico diferencial.

Revolucionário de primeira hora, Cabanis participa das conspirações e embates políticos que derrubaram o antigo regime. Após a tomada da Bastilha, conhece Honoré-Gabriel de Mirabeau, com quem colabora em diferentes ocasiões; durante 1790, redige vários discursos por ele proferidos na Assembleia Nacional, ajudando-o a se tornar um dos maiores oradores e líderes políticos da Revolução Francesa. Após a morte precoce de Mirabeau em 1791, Cabanis revisa e mesmo reescreve suas anotações para discursos sobre educação e os reúne numa publicação intitulada Quatre Discours sur l'Éducation Publique, concedendo créditos exclusivos ao grande tribuno.

Entre 1790 e 1792, Cabanis torna-se administrador geral dos hospitais de Paris. Como programa de trabalho, publica o ensaio Observations sur les Hôpitaux, apoiando a reforma conduzida por Philippe Pinel. Em 1791, elege-se vice-prefeito da comunidade de Auteuil, confirmando-a como sua terra de adoção. No início da Convenção, apresenta relatórios sobre instrução pública e assistência social que muito influenciam as medidas de reestruturação institucional implantadas pela Revolução Francesa. Nesses textos, considera a distribuição injusta de riqueza do antigo regime como o maior problema político enfrentado pela Revolução e propõe estratégias de redução das desigualdades sociais mediante radical reorganização do Estado. Nessa fase, inicia forte amizade e colaboração com o pedagogo e filósofo Destutt de Tracy, organizando o movimento intelectual que a posteridade chamaria de Les Idéologues 13,18.

Em 1793, no auge do terror, ajuda a esconder o Marquês de Condorcet nos arredores de Paris, acolhendo toda a família do amigo perseguido (três anos depois, Cabanis se casaria com Charlotte Grouchy, cunhada de Condorcet). Nesse período turbulento, Cabanis sofre muito com a prisão de seus amigos mais próximos, culminando com a execução de Lavoisier e do poeta Roucher, seu mentor da juventude, e o suicídio de Condorcet. Deprimido, doente e considerado suspeito pelo regime, Cabanis recolhe-se a Auteuil onde retoma sua clínica de pobres e desvalidos (que enfim o protegem da perseguição das milícias populares).

Em meados de 1794, quando o terror finalmente começa a refluir, Cabanis retoma intensa atividade política. Reabre os salões de Madame Helvétius, agora acolhendo o núcleo aglutinador do que Picavet 13 chamou de "segunda geração dos ideólogos": Pierre-Simon Laplace, célebre matemático, astrônomo e físico; Jean-Baptiste Say, pioneiro das ciências econômicas; Constantin-François de Volney, historiador que introduz Napoleão Bonaparte no grupo; François Daunou, educador e precursor da ciência política; liderados por de Tracy e pelo próprio Cabanis. 
Colaborando com Pinel, Cabanis renova seu interesse pelos temas de reforma dos hospitais, regulamentação do exercício da profissão médica, teoria das práticas clínicas, modelos assistenciais e ensino médico. Um plano moderado de reforma da medicina e do ensino em saúde, elaborado por uma comissão presidida por Vic D’Azyr, tinha sido apresentado à Assembleia Nacional no primeiro ano da Revolução Francesa, logo rejeitado por sua origem numa instituição oficial do regime anterior. Em 1794, o projeto de reforma do ensino médico apresentado por Fourcroy à Convenção, mencionado na introdução, preconiza uma formação de base anatomoclínica e introduz o conceito de estágio obrigatório nos serviços de saúde (origem do internat des hôpitaux). Cabanis apoia esses pontos da proposta, porém discorda da farmacoquímica como ciência de base do novo currículo e da criação das écoles de santé. Apesar disso, é nomeado professor adjunto de hygiene da primeira escola de saúde implantada em Paris, junto com Pinel, Fourcroy e Thouret.

Após a reabertura das faculdades, Cabanis é nomeado professor adjunto da Faculdade de Medicina de Paris, onde implanta um novo modelo de ensino clínico. Seguidor da "semiologia natural" de Corvisart, defende examinar o paciente em profundidade, numa abordagem sistemática e metódica, observando a correlação nosológica diretamente na cabeceira do paciente. Cabanis escreve em 1796 um texto sobre a escola de medicina ideal, intitulado Considérations Genérales sur les Révolutions de l'Art de Guérir, discutido no Institut de France.

Em 1798, graças ao seu trabalho filantrópico em Auteuil, elege-se representante do Departamento de Seine no Conselho dos Quinhentos. Aproveitando sua tribuna, propõe ajustar o Plano Vic d'Azyr à proposta de Fourcroy, apresentando sucessivos rapports ao Conselho durante seu mandato. $\mathrm{O}$ mais importante desses documentos é sem dúvida Sur un Mode Provisoire de Police Médicale 19, proposta de políticas para reinstitucionalização do exercício da medicina (esse é o sentido do termo police médicale) na era pós-revolucionária, em sintonia com diretrizes curriculares e regras de graduação em nível superior para a profissão médica. Político habilidoso e bem relacionado, Cabanis mostra-se atuante na condição de parlamentar e consegue, não sem dificuldades, aprovar a maior parte de seus projetos.

Em 1799, de volta do Egito, Napoleão Bonaparte dá sinais de que pretende adotar as ideias defendidas pela elite intelectual parisiense, com maior simpatia pelas propostas do grupo liderado por Cabanis e Destutt de Tracy. Entusiasmado bonapartista, Cabanis participa do golpe de Estado do 18 Brumário e é convocado a compor o Senado Conservador durante sua criação. Nesse ano, despontando no cenário acadêmico parisiense, é nomeado para a cátedra de História da Medicina da Faculdade de Medicina de Paris.

Na virada do século, Madame Helvétius falece e deixa Cabanis como herdeiro. Como muitos dos seus colegas ideólogos, Cabanis esperava que os princípios republicanos defendidos pela Revolução fossem aplicados na reconstrução da sociedade francesa, porém se decepciona com o autoritarismo de Napoleão, já Cônsul Vitalício da República; em protesto, não mais comparece às sessões do Senado. O estado de guerra permanente e o patriotismo exacerbado que dominam a sociedade francesa na era Bonaparte acentuam seu isolamento e depressão. Cabanis recolhe-se à biblioteca de Auteuil e empenha-se em registrar de modo sistemático seu legado filosófico, científico e pedagógico.

Em 1802, publica Rapports du Physique et du Moral de l'Homme, obra que gerou grande polêmica ao propor uma teoria fisiológica sobre a origem das ideias que, de modo explícito, negava a existência da alma. Em 1803, com a reconstituição das academias com base nas seções do Institut de France, Cabanis é eleito para a entidade que posteriormente se tornaria a Academia Francesa. Nesse mesmo ano, organiza seus escritos sobre história dos saberes em saúde, reforma da medicina e educação médica, no entanto, por razões de saúde, não conclui a revisão e ampliação planejadas; apesar disso, atendendo à pressão dos amigos, autoriza sua publicação como livro-testamento. A partir de 1805, sua delicada saúde piora bastante; impossibilitado de sair do refúgio em Auteuil, desgostoso com a tirania do governo bonapartista, encerra sua carreira política. Georges Cabanis falece no dia 5 de maio de 1808, devido a acidentes vasculares encefálicos 18 . 


\section{Revoluções e reforma da medicina}

Anotações escritas durante o inverno de 1795, aulas sobre história da medicina ministradas na Faculdade de Medicina de Paris entre 1797-1798 e propostas sobre reforma do ensino médico submetidas ao Conselho dos Quinhentos entre 1798-1801, foram integradas num volume intitulado Coup d'Oeil sur les Révolutions et la Réforme de la Médecine (Coup d'Oeil) 20, somente publicado em 1804, como se viu. Propõe-se, aqui, tomar esse fascinante documento, representativo do pensamento político-filosófico cabanisiano, cujo frontispício encontra-se na Figura 2, como peça-chave para a presente análise.

O título dessa obra justamente indica um balanço do esforço coletivo de reforma da medicina, vitorioso na criação de um modelo de prática médica que, já em 1803, mostrava-se funcional e promissor. Entretanto, sua tábua de conteúdos (Figura 3) revela que se trata de detalhado projeto de resgate da história da prática médica e de reforma da educação médica, ambicioso em termos conceituais, curriculares, pedagógicos e pragmáticos

No Coup d'Oeil, encontra-se uma advertência prévia do autor que narra circunstâncias, motivação e dificuldades (inclusive de saúde) para a elaboração do livro. Como introito, Cabanis confessa que sempre buscou contribuir para o grande projeto político de seu amigo Garat: a reorganização do sistema francês de ensino em todos os setores e níveis. De fato, Cabanis colaborou com o Comité d'Instruction Publique, presidido por Dominique Garat, que conseguiu inserir na Constituição, aprovada pela Assembleia Constituinte em 1791, a garantia da educação como direito de todos.

Figura 2

Frontispício da obra Coup d'Oeil sur les Révolutions et la Réforme de la Médecine 20.

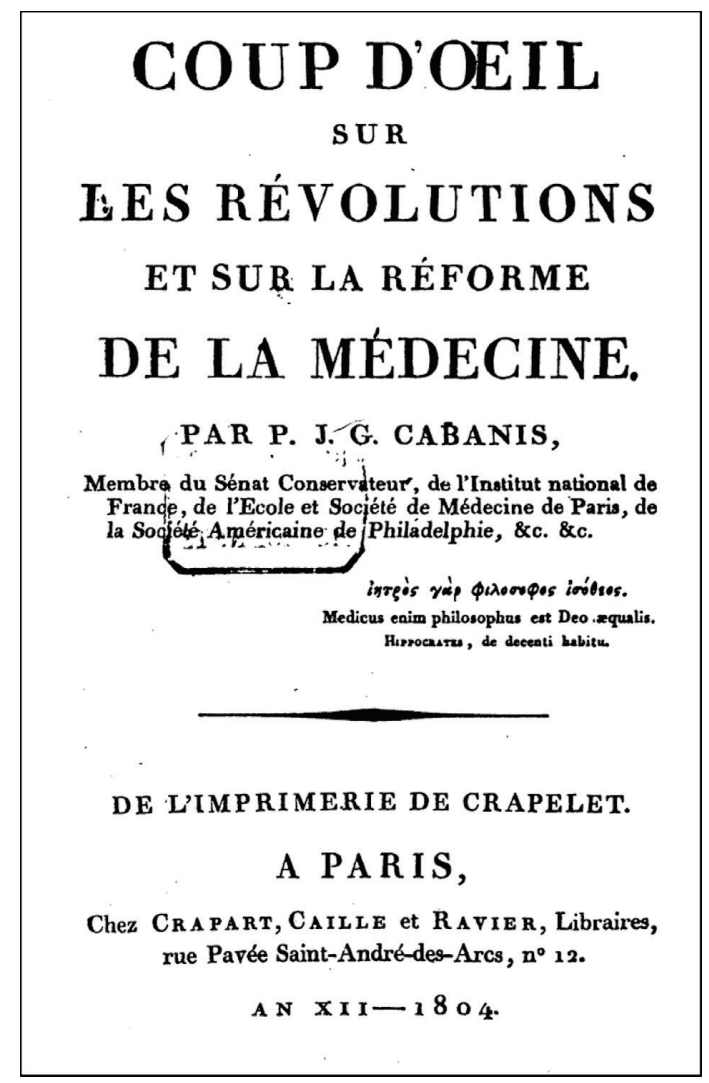


Figura 3

Tábua de conteúdos do livro Coup d'Oeil sur les Révolutions et la Réforme de la Médecine 20.

\begin{tabular}{|c|c|}
\hline T A B L E. & \\
\hline 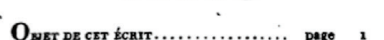 & 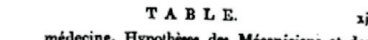 \\
\hline 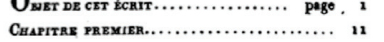 & 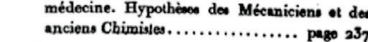 \\
\hline $\begin{array}{l}\text { S. x. L'art de guérir est-il fondé our des bases } \\
\text { solides ?........................... ibid. }\end{array}$ & $\begin{array}{l}\text { 5. } x \text {. La Medecine tend aux bypothices, par ha } \\
\text { nature meme du sujet auquel elle o'applique. 25t }\end{array}$ \\
\hline 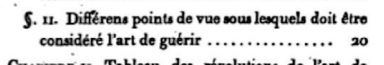 & 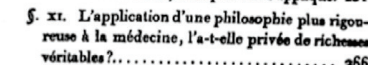 \\
\hline 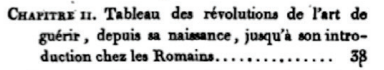 & 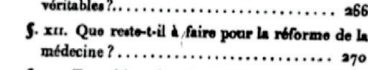 \\
\hline $\begin{array}{l}\text { S. I. La médecine entre les mains des chefu do } \\
\text { peuplades, des poètes, et surtoat des protres. ibid. }\end{array}$ & 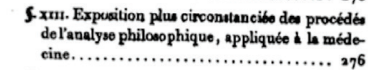 \\
\hline 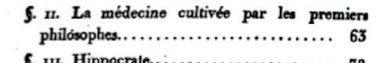 & 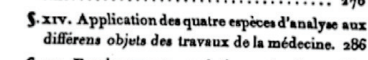 \\
\hline 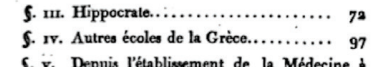 & $\begin{array}{l}\text { S. xv. Enseignement analytique do lo mbde- } \\
\text { cine................................. } 3 \text { 3o7 }\end{array}$ \\
\hline $\begin{array}{l}\text { S. v. Depuis Yétablissement de la Médecine } \\
\text { Rome, jusquă Y'époque des Arabes ..... } 106 \\
\text { S. v. Époque des Arabes.............. } 116\end{array}$ & $\begin{array}{l}\text { Chapriaz iv. Considérations particulières our diver- } \\
\text { oes branches de la Médecine............ } 514\end{array}$ \\
\hline $\begin{array}{l}\text { S. vn. La Médecine passe de Grèce en Europe, } \\
\text { avec les savans et les livres............. } 123\end{array}$ & 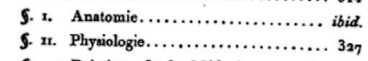 \\
\hline $\begin{array}{l}\text { 5. vin. Médecins Juifs ................. } 125 \\
\text { 5. 1x. Médecins Chimistes de la première épo- }\end{array}$ & 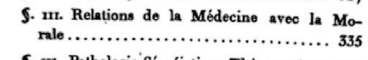 \\
\hline 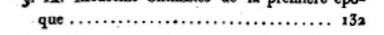 & 5. Iv. Pathologie,Séméiotique, Thérapeutique. 345 \\
\hline 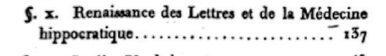 & 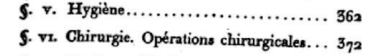 \\
\hline 5. xi. Staalh, Vaubelmont ......... page 145 & S. vu. Matière médicale ................ 378 \\
\hline & 5. vur. Chimie, Pharmacie.................. 384 \\
\hline 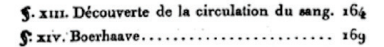 & S. xx. Botanique ................ page $38_{9}$ \\
\hline $\begin{array}{l}\text { S. xv. Hoffmann; Baglivi; nouveaux solidistes } \\
\text { d'Edimbourg ; Ecole de Montpellier } \ldots \ldots \ldots .173\end{array}$ & 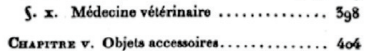 \\
\hline S. xvr. État de l'enseignement . ............ 177 & 5. $x$. Histoire naturelle................. ibid. \\
\hline 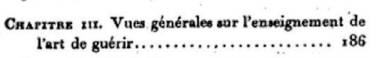 & $\begin{array}{l}\text { S. In. Phyodique } \ldots \ldots \ldots \ldots \ldots \ldots \ldots \ldots \ldots \\
\text { S. III. Sciences mathématiques.............. 41x }\end{array}$ \\
\hline $\begin{array}{l}\text { 5. I. Fa cultés de l'homme; rource de ses erreurs; } \\
\text { inventions des mólhodes philosopbiques. . ibid. }\end{array}$ & 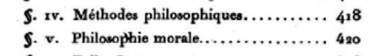 \\
\hline 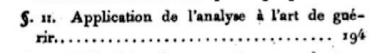 & $\begin{array}{l}\text { S. vi. Belles-Lettres et Arts ............. } 426 \\
\text { S. vix. Langues anciennes et modernes.... } 450\end{array}$ \\
\hline 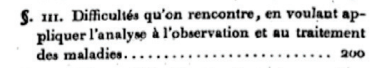 & ConcLtston $\ldots \ldots \ldots \ldots \ldots \ldots \ldots \ldots \ldots, 435$ \\
\hline $\begin{array}{l}\text { 5. Iv. Memes difficultes iet memes dangers dans } \\
\text { la classification des remèdes.................. } 204\end{array}$ & \\
\hline $\begin{array}{l}\text { S. v. Tentatives failes pour perfectionner les } \\
\text { elassifications médicales..................207 }\end{array}$ & \\
\hline S. vi. Difficultés nouvelles................ 210 & \\
\hline $\begin{array}{l}\text { S. vil. On revient toujours necessairement ì la } \\
\text { méthode. Elle ne nuit jatmais par elle-méme. } \\
\text { Comment elle doit tere appliquée à la méde- } \\
\text { cine................................ at5 }\end{array}$ & \\
\hline 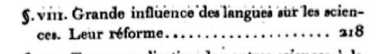 & \\
\hline 5. Ix. Fausse application des autres sciences ì la & \\
\hline
\end{tabular}

No prólogo, intitulado simplesmente Objet de Cet Écrit 20, Cabanis apresenta com precisão os objetivos da obra, contrastando com o estilo rebuscado predominante na literatura acadêmica daquela época:

- traçar, de maneira rápida e sumária, a história das revoluções da medicina;

- caracterizar cada revolução pelas circunstâncias que a fizeram surgir e pelas mudanças que ela produziu no desenvolvimento da ciência;

- e, enfim, tentar ver se os diferentes quadros, comparados aos métodos filosóficos modernos, podem fornecer algumas visões úteis para a reforma da medicina e do seu ensino.

Ao dar conta do primeiro objetivo do Coup d'Oeil, Cabanis demonstra uma perspectiva inusitada de respeito aos saberes tradicionais, antecipando as bases relativistas da ciência antropológica. Menciona que mesmo entre os povos mais primitivos (destaca Nova Zelândia, Lapônia, América do Norte e interior da África) de sua época encontram-se "vestígios de uma medicina e de uma cirurgia verdadeiras". 
De imediato, transporta tal analogia para a era pré-histórica, postulando que saberes pertinentes à saúde eram coletivamente apropriados e práticas de saúde "podiam ser exercidas por todas as pessoas dotadas de alguma inteligência" que, ao assumir o papel de cuidador da saúde numa tribo ou aldeia, eram capazes de reconhecer diferentes doenças e aplicar tratamento mais ou menos eficientes.

Cabanis propõe peculiar periodização para a pré-história da medicina, correspondente ao papel social dos protomédicos: primeiro, poetas, registrando sentimentos e sofrimentos; depois sacerdotes, com "a linguagem vaga e o sotaque misterioso da superstição"; finalmente, filósofos, que "adotaram princípios de várias ciências que ainda não estavam prontas”. As menções pouco honrosas à competência dos sacerdotes para cuidados em saúde resultam do anticlericalismo dominante entre os ideólogos representativos do materialismo revolucionário. De todo modo, para Cabanis, os filósofos teriam sido responsáveis pela primeira revolução referida no título de sua obra: “A revolução que os primeiros filósofos fizeram na arte de curar (...) todas as ciências que se encontravam ainda no berço, tornaram-se simultaneamente objeto de suas meditações. (...) Quando estes sábios voltaram seus olhares para a medicina, puderam começar a clareá-la com uma luz mais pura. Acostumados a organizar seus diversos conhecimentos em uma certa ordem, a procurar relações entre eles e a encadeá-los, viram como era indispensável a classificação das observações médicas, para que pudessem ser submetidas ao exame do raciocinio. (...) Estes filósofos (...) transformaram uma doutrina oculta e sacerdotal em ciência comum, em arte usual. Esta revolução foi infinitamente útil, [tanto...] para a medicina como para a filosofia" 20 (p. 65-6).

Os fundamentos da medicina hipocrática são transversalmente apresentados por Cabanis em 24 páginas do Coup d'Oeil, com ênfase na teoria da saúde como equilíbrio dinâmico entre ambiente e sujeito enfermo, na doutrina dos humores e na doutrina médica das crises. Em todo o texto, Cabanis se esmera em contextualizar suas relações com escolas filosóficas e outras tradições terapêuticas, narrando episódios e casos, sempre num tom apologético, sem esconder sua imensa admiração pelo "pai da arte de curar". Além da contribuição à constituição de uma "medicina em sua via natural", com base numa racionalidade empírica, Cabanis afirma Hipócrates como autor da crucial separação entre medicina e filosofia que dialeticamente permitiu recompor "essas duas ciências uma para dentro da outra”, recriando-as por meio de relações absolutamente novas.

Galeno comparece no Coup d'Oeil como o mais ilustre dos médicos romanos de origem grega, que reviu fundamentos da doutrina hipocrática, fez observações próprias e buscou integrar as diversas teorias vigentes em sua época. Galeno teria recriado à sua maneira a medicina grega, ampliando sua influência entre as dezenas de seitas que cuidavam da saúde na Roma Antiga. Comenta Cabanis que ao adquirir, nas aplicações galênicas, caráter mais sistemático e até empresarial, a arte/ciência criada por Hipócrates teria perdido "muito de sua pureza", constituindo "mais um adereço do que uma verdadeira riqueza".

Na seção pertinente à medicina árabe, Cabanis revela-se um crítico ácido, injusto e até mesmo incompreensível. Sem citar fontes, valoriza a tradição ptolomaica da Escola de Alexandria, em que a arte de curar teria sido "ensinada brilhantemente" a estudantes "de todos os cantos, que vinham ouvir os mestres mais célebres do universo". Imputa a destruição da mais famosa biblioteca da história ao "ignorante furor dos muçulmanos", assinalando que a destruição foi menor para os livros de medicina, "por causa do interesse que inspira aos homens mais ignorantes - a ciência que promete o alívio dos males” 20 (p. 124). Para Cabanis, a medicina árabe pouco teria contribuído para a história da arte de curar.

"As escolas árabes estavam na moda, como as escolas gregas já o tinham sido antigamente. O árabe se tornou a língua dos sábios. Foi através desta língua que a Europa conheceu, primeiramente, as obras de Hipócrates, Galeno, Aristóteles, Euclides e Ptolomeu. Entretanto, no meio deste movimento dos conhecimentos, a medicina não tinha feito nenhum progresso real" 20 (p. 124).

No Coup d'Oeil, Cabanis praticamente ignora a contribuição dos médicos-filósofos árabes, sequer nomina Averróis e Avicena, a despeito do Cânon de Medicina de Avicena ter feito parte da bibliografia obrigatória das escolas médicas europeias até o século XVII 21. Pior ainda: aos médicos-filósofos da Pérsia e de Córdoba (Espanha), Cabanis deixa implícita a acusação de plagiadores, saqueadores e usurpadores das raízes gregas da medicina moderna. Em contraste, Cabanis valoriza sobremaneira o papel dos médicos judeus durante a Idade Média. Em tom quase mítico, atribui aos judeus o estabelecimento da rede de relações comerciais e financeiras, pela "intima fraternidade que os unia em todas as partes do mundo", que lhes permitia operar meios seguros para o deslocamento dos valores monetários. Segundo Cabanis, apesar da "perseguição cruel e constante da qual eram as infelizes vítimas em todas 
as partes do mundo conhecido, (...) eles eram nossos carteiros e nossos banqueiros, antes que soubéssemos ler" e "foram também nossos primeiros médicos" 20 (p. 125). Em um tempo em que Hipócrates e os outros pais da medicina eram conhecidos no Ocidente somente pelas traduções árabes, "os judeus eram quase os únicos que sabiam tratar as doenças com algum método" 20 (p. 126).

Comenta Cabanis que tal domínio da arte de curar resultava de uma rede de escolas em Toledo, Córdoba e Granada (Espanha) e no Oriente Médio, onde "a medicina era ensinada com um cuidado todo especial”, omitindo que todas essas escolas se situavam em territórios dominados pelo Islã e desprezando registros históricos da estreita colaboração dos médicos judeus na prática da medicina em diferentes califados. Sua narrativa revela grande respeito e admiração em relação aos judeus, atribuindo-lhes uma personalidade modal que, para além do estereótipo negativo de agiotas usurários, vigente em sua época, implicava predisposição e mesmo talento para a prática eficiente da medicina.

Cabanis destaca a evolução da química como a revolução científica de maior impacto - "a chave geral de todas as ciências naturais, a verdadeira luz das artes industriais" - para a emergência de uma medicina de base científica na transição do Renascimento ao Iluminismo. Num tempo em que a população sofria com "preconceitos científicos", os alquimistas desenvolviam "princípios do sistema natural". Paracelso, o mais famoso dos alquimistas, é definido por Cabanis como "um verdadeiro modelo de arrogância, audácia e demência" 20 (p. 135).

Nessa altura, Cabanis nos apresenta a Georg Ernst Stahl (1659-1734), médico-alquimista que, em sua opinião, seria "o maior médico desde Hipócrates", um dos "primeiros a transformar a filosofia em ciência". Sem indicar referências, considera-o grande conhecedor da matéria médica e comenta que ninguém melhor que ele seria capaz de integrar "as observações e os pensamentos filosóficos dos modernos" à secular arte da cura. Cabanis demonstra grande admiração por essa personagem quase esquecida na história das ciências, a ponto de a ele dedicar dez páginas do Coup d’Oeil.

Considerados por muitos autores como fundadores da moderna clínica médica, dois neo-hipocráticos históricos - Thomas Sydenham (1624-1689), na Inglaterra; Herman Boerhaave (1668-1738), na Holanda - são destacados por Cabanis, num misto de admiração respeitosa e crítica invejosa, cada um merecendo uma seção inteira no Coup d'Oeil.

Para Cabanis, a medicina praticada e ensinada na Inglaterra na virada do século XVIII "era totalmente escolástica" e o "verdadeiro espírito de observação era quase totalmente desconhecido" 20 (p. 160-1). Oficial do exército de Cromwell, Sydenham harmonizou uma carreira militar paralela à prática clínica, exercida inicialmente sob licença precária do College of Physicians. Segundo Cabanis, Sydenham "não conhecia muito bem as teorias que reinavam naquele momento" e, sem acesso a livros caros naquela época, sequer teria estudado Hipócrates. Talvez Cabanis tivesse razão, pois Sydenham completou seus estudos de doutorado na Universidade de Cambridge (Reino Unido) somente aos 56 anos de idade 22. Contudo, Cabanis admite que os novos conceitos de prática clínica que revolucionaram a medicina inglesa e depois influenciaram todo o Norte da Europa são devidos a Sydenham; por isso declara por ele sincera admiração. Não obstante, as referências no Coup d'Oeil revelam profunda ambivalência em relação a Sydenham.

Na seção dedicada a Herman Boerhaave, Cabanis traz poucas informações sobre vida e obra desse médico e professor que Foucault considera como o mais ilustre e influente dos precursores da clínica moderna. Em tom opinativo e quase sarcástico, prefere apresentá-lo como um estudioso sistemático e metódico, mas não muito criativo, que teve a medicina como última escolha, depois de breve incursão na teologia e que, durante algum tempo, sobreviveu como professor de matemática e física. Reconhece, quase com relutância, os "conhecimentos profundos e vastos" de Boerhaave quase como obstáculo ao sucesso numa carreira médica temporã, na medida em que sua inegável inteligência teria "adquirido muito em força, em desenvolvimento, em hábito de discussões, em tenacidade de atenção, mas sua percepção nunca chegou a um grau de perfeição" 20 (p. 170).

Cabanis conclui esse capítulo sobre a história da medicina com uma reflexão, quase confessional, sobre a relação entre a história da prática clínica e a evolução do ensino médico. De início, sombrio, avalia que, nos séculos XVI e XVII, "o progresso da ciência foi grande e rápido, entretanto, em compensação, o progresso do ensino foi quase nulo" 20 (p. 181). Atribui essa defasagem ciência vs. ensino às "concepções servis da maior parte dos professores" e ao "discurso confuso da escolástica" que geravam grande distância entre a doutrina e a escola, "entre a sábia ousadia e a rotina cega". Em contraste, celebra os "verdadeiros progressos” do Iluminismo no campo do ensino durante a segunda metade do século XVIII. 
Para a reforma da medicina, tornando-a moderna do ponto de vista científico, Cabanis prescreve teoria rigorosa e metodologia empírica sistemática, aplicada por profissionais capazes de operar novos conceitos, métodos e técnicas. E para isso, é necessário "que o ensino da medicina (...) forme para a prática pensadores profundos, desenvolvidos, firmes e flexíveis, que encontrem nas luzes de uma razão transcendente, esse conhecimento da vida e essa sabedoria de aplicação” 20 (p. 7). Como estratégia orientadora desse modelo de ensino médico, propõe adotar uma nova ordem de exposição dos fatos, com métodos seguros de observação, experiência e raciocínio, componentes de uma agenda pedagógica renovada.

\section{Uma nova pedagogia (para uma nova) clínica}

Considerando os subsídios arrolados, Cabanis se sente enfim capacitado a elaborar sua concepção de "ensino analítico da medicina" com base em dois pontos. Primeiro, a necessária convergência ideológica entre as revoluções da medicina e do ensino médico. Segundo, a pauta dessa revolução, que combina reengenharia institucional (un bon plan d'écoles) e um novo sistema de ensino (systême de leçons). Como a recriação do sistema de instrução pública foi alcançada mediante luta política específica, trata-se aí de implantar um projeto pedagógico revolucionário, que implica uma didática e uma arquitetura curricular consistentes com a base epistemológica integradora da física e da moral, por uma nova metodologia com tripla amplitude de aplicação: na pesquisa, na clínica, na educação.

A pedagogia revolucionária compreende uma didática naturalista, em que a "verdadeira instrução dos jovens médicos é aquela que eles recebem no leito dos doentes e não nos livros, nem em uma fria escola, e sim na presença da própria natureza, (...) que fornecia o texto das lições” 20 (p. 308). Pedagogia revolucionária, mas não necessariamente inovadora, pois "os gregos ensinavam a medicina prática no próprio leito dos doentes, (...) daí o nome de clínica”, e em Roma, "os médicos mais reconhecidos levavam seus alunos para a casa dos doentes”. Por outro lado, essa pedagogia, pretendendo ser analítica, traduz-se numa arquitetura curricular fragmentada em matérias, numa trajetória gradual e linear, congruente com a análise de decomposição-recomposição justificada por uma epistemologia cartesiana. Nas palavras de Cabanis 20 (p. 307): "[Trata-se de] apresentar aos alunos os objetos sempre na ordem mais natural, quer dizer, começar pelos objetos mais conhecidos ou pelos mais fáceis de serem conhecidos. Sucessivamente e gradualmente, passar para aqueles que demandam uma observação mais profunda, os sentidos mais aguçados ou mesmo novos instrumentos".

Cabanis apresenta uma proposta de organização do currículo médico que em termos gerais de estrutura permanece vigente por pelo menos dois séculos. Enumera como matérias obrigatórias: Anatomia, Fisiologia, Patologia, Ciências da Moral, Semiótica, Nosologia, Química, Farmácia, Botânica, Higiene, Terapêutica, Matéria Médica, Cirurgia, Medicina Veterinária. E como matérias complementares, que denomina de "objetos acessórios": História Natural, Física, Ciências Matemáticas, Métodos Filosóficos, Filosofia Moral, Letras e Artes, Línguas Antigas e Modernas. Três inserções requerem contextualização: Ciências da Moral, que inclui temas psicológicos e sociológicos (ideias, sentimentos, paixões, virtudes e vícios) de interesse médico; Matéria Médica, que se refere ao conjunto de tecnologias aplicadas ao tratamento e cura; e Medicina Veterinária, área de grande potencial para a nascente cirurgia experimental. A rápida evolução do conhecimento científico nesse período determinou ajustes em conteúdos e na estrutura curricular, com desmembramento de matérias e emergência de novas disciplinas.

Veja-se a questão da pedagogia como método prático análogo ao método clínico, finalmente compreendido como aplicação do método científico aos eventos singulares ou casos. Evidentemente, Cabanis pretende construir uma equivalência secundária entre métodos práticos - da terapêutica em medicina à prática pedagógica no ensino médico - em que as regras da clínica "só podem ser desenvolvidas na cabeceira do doente" do mesmo modo que as regras da didática se aplicam na interação mestre-aprendiz. A aplicação dessas regras (outra fórmula para o conhecimento em ato) "só poderá ser bem compreendida depois de longa sequência de exemplos", esgotando, pela repetição, todas as combinações possíveis. Consistente com sua teoria das ideias, para Cabanis, aprender é memorizar um dado conhecimento para aplicá-lo com precisão na prática clínica: "[Nesse processo] é preciso, sobretudo, que esses exemplos deixem na memória [dos estudantes] imagens indeléveis que servirão para reconhecer, no primeiro olhar, o caráter distinto de cada doença, no meio de todas as complicações que podem mascará-lo" 20 (p. 217). 
Tal como as doenças assumem ampla diversidade de formas, o ensino médico se compõe de matérias de diferentes tipos, distintas também na maneira pela qual podem ser aprendidas. Algumas se desenvolvem bem por meio de lições escritas "ou nas sábias palestras de um bom professor", podem ser reproduzidas em livros, por várias vezes e sob novas formas. Porém, matérias desse gênero são muito poucas.

"Em todas as outras, o professor só poderá ser bem entendido se estiver na presença dos objetos. Querer pintar um músculo, uma doença, uma operação química para aquele que nunca viu esta operação, esta doença e nem este músculo, é querer fazê-lo experimentar o sabor de um fruto que ele não conhece ou o odor de um perfume que ele nunca sentiu" 20 (p. 355).

Cabanis nos faz uma advertência: "não é preciso levar a prática deste método à pedantérie" 20 (p. 309). Com elegante ironia, fala dos arrogantes catedráticos, porta-vozes da pomposa pedagogia retórica da universidade clássica, aquela que teria sido enterrada com o Antigo Regime, prestes a serem superados por um novo perfil de professor, mais comprometido com o ensino dos estudantes do que com a afirmação do seu saber magistral.

"...Mais do que apresentar ideias inesperadas e surpreendentes por sua grandeza ou por sua novidade, o professor deve excitar o interesse e despertar a curiosidade dos alunos. Conforme o caráter dos objetos, o professor deve passar da análise à síntese e da sintese à análise, corrigindo sempre as indicações mais audaciosas da síntese com a ajuda das formas mais regulares e seguras da análise" 20 (p. 310-1).

Enriquecido pela disciplinada condução de observações e registros, em ciclos de permanente reavaliação, aplicando conceitos e pensamentos pertinentes, tal método prático deve retificar, insistentemente, o que outros métodos, "presos na teoria, apresentam como absoluto e rigoroso" 20 (p. 216-7). Para Cabanis, o "instinto, mais do que o saber", permite ensaiar as regras provisórias desse método de ensino. No entanto, para "que se possam traçar regras verdadeiras, o saber as esclarece e as amplia, o espírito filosófico as encadeia e as coordena", e o instinto "aperfeiçoa, sobretudo, sua aplicação", quando nesse momento "o método se confunde com o talento" 20 (p. 217). Essa dupla valorização do instinto, como fonte do talento e condição da resolutividade, introduz elementos não analíticos numa proposta de pedagogia analítica, tornando recomendável e mesmo justificando a ênfase no fazer (devidamente supervisionado por mestres compreensivos e experientes) como projeto de ensino-aprendizagem.

Para cumprir etapas cruciais na transição de uma revolução científica para revoluções na medicina e no ensino médico, determinadas pelo progresso das ciências do físico e do moral 23, Cabanis 20 (p. 216) propôs recorrer às "operações de nossa inteligência" a fim de criar "um método experimental e prático, fruto da observação contínua dos objetos e do emprego repetitivo dos instrumentos" (de pesquisa e de ensino). Não obstante a refinada construção teórica, restava uma tarefa hercúlea, em nada trivial: um cuidadoso trabalho de costura política em muitas frentes, especialmente em sua função legislativa como parlamentar, num rico momento de reconstrução de uma nova sociedade civil e de um Estado republicano, após a queda do Ancien Régime. Nesse contexto, a narrativa autoral e panorâmica dessa intrigante obra explicita os fundamentos do que se propõe, aqui, designar como Reforma Cabanis.

\section{Reforma Cabanis: o império das faculdades}

Em O Nascimento da Clínica 3, Foucault concede pouca atenção ao Coup d'Oeil. Mais focado numa história crítica da medicina como dispositivo organizador de práticas sociais, toma como fio condutor de sua análise operações discursivas normalizadoras de condutas propedêuticas e semiológicas. Interessa-se pouco pelos conhecimentos e métodos advindos da recriação do ensino médico como processo político e institucional que repercutiria na reorganização da educação superior francesa como um todo. Dessa forma, enfatiza a oficialidade e legalidade do que Clavreuil chamaria de "ordem médica", nova configuração das práticas de intervenção em saúde 24,25,26.

Interessado em Cabanis, sobretudo como reformador do sistema francês de assistência à saúde, Foucault concentra-se na análise da proposta da police médicale submetida ao Conselho dos Quinhentos. Nesse texto 19, Cabanis aborda a natureza (social, cultural, institucional) da medicina e do cuidado em saúde e propõe, em linhas gerais, uma teoria da economia política da profissão médica capaz de justificar intervenções profundas na incipiente rede social de assistência em saúde, estratégica para o projeto político da Revolução Francesa. Cabanis distingue duas categorias de bens ou objetos eco- 
nômicos. Para alguns objetos ou mercadorias, os próprios consumidores podem avaliar sua utilidade pelo uso, o que seria suficiente para determinar seu valor. Porém, o valor de outros objetos não pode depender dessa avaliação direta, ou por serem necessários para fixar o valor de outros (como a moeda, incluindo metais preciosos) ou por envolverem riscos à pessoa humana, situação em que qualquer erro ou fraude se torna fatal. Em ambos os casos, como observa Foucault, tanto num mercado real de troca de ativos monetários quanto num quase-mercado de riscos, danos virtuais e bens voláteis (como a saúde), objetos ou serviços têm valor intrínseco e potencial não imediatamente visível, inevitavelmente vulnerável a erros. Para regular a produção e utilização desses objetos, bens ou serviços, mais do que controle de mercado (diretamente pela oferta e demanda num regime liberal de compra e venda) e controle social pela aceitação tácita de seu valor de uso, a nascente República precisa organizar estrutura e funcionamento de dispositivos de regulação e controle do Estado sobre a economia, o que inclui sem dúvida o campo da saúde e a prática médica.

A questão central dessa conjuntura então se apresenta com clareza: como atribuir à corporação médica proteção institucional e reserva de mercado, sem retroceder às estruturas corrompidas e perversas do Antigo Regime, nem recair em formas arbitrárias de controle do Estado que poderiam trair os valores republicanos? Uma questão preliminar e fundamental seria a delimitação do conjunto de sujeitos que, pelo controle institucional dos órgãos de governo, poderia formar essa nova corporação de profissionais. Para solucionar tal questão num momento de grave carência de pessoal, Cabanis prioriza dois problemas práticos: o credenciamento do exercício profissional dos médicos práticos e o reconhecimento dos oficiais de saúde formados. Engenhosamente, propõe adotar uma única estratégia para resolver os dois problemas: um exame de Estado que, para os oficiais de saúde, será limitado ao "conhecimento fundamental da arte, e (...) à sua prática", mas que, para a validação de estudos médicos regulares, devem incluir provas escrita e oral, bem como "exercícios de anatomia, cirurgia e medicina clínica”. O Estado se encarregará de fiscalizar com rigor o exercício profissional: "Todo aquele que praticar medicina sem exames ou escola sem ser colocado perante os júris especiais serão multados e condenados à prisão em caso de reincidência" 3 (p. 91).

Foucault relata que a proposta de Cabanis não foi aceita nessa oportunidade, mas, "nas suas linhas fundamentais, sinalizou uma solução que dotaria a medicina do estatuto de profissão liberal e protegida que ela manteria até o século $X X X^{\prime \prime} 3$ (p. 90). De fato, a legislação sobre a prática da medicina em França, finalmente aprovada pelo Consulado em 1802, mostra-se consistente com as propostas de Cabanis em todas as suas dimensões. Por um lado, estabelece uma hierarquia de dois níveis na profissão médica: doutores em medicina e cirurgia graduados em uma das seis faculdades autorizadas; e agentes de saúde, remanescentes das écoles de santé (substituídas pelos novos estabelecimentos oficiais de ensino médico). Qualquer cidadão fora dessas categorias que se arrisque a praticar a medicina incorrerá em penalidades, de multas à prisão. Por outro lado, conforme preconizado por Cabanis, introduz-se o licenciamento para o exercício profissional mediante aprovação em quatro exames (anatomia e fisiologia, patologia e nosologia, materia medica, higiene e medicina legal), além de uma prova prática de medicina interna ou externa, respectivamente para os que querem ser médicos ou cirurgiões.

Ao extinguir as universidades francesas, a Revolução de 1789 produziu uma solução política radical: o que era uma instituição de cultura e do conhecimento se tornou uma instituição promotora de formação técnica e profissional, ou seja, vocacional. Além da criação de "universidades nominais", o sistema se caracteriza igualmente pela forte segmentação de qualidade entre universidades e Grandes Écoles e entre formação e investigação 7. Com esse regime institucional, dominado por faculdades e escolas isoladas e relativamente independentes das universidades, é justamente nessa fase histórica que se propõe uma arquitetura curricular linear e exclusiva para formação em carreiras profissionais mediante o ensino superior cada vez mais especializado, sobretudo na esfera da educação médica 25 .

Concretizada durante o período napoleônico, a Reforma Cabanis resultou enfim em faculdades dotadas de autonomia e capacidade para decidir sobre normas, disciplinas e cursos, bem como uma rede de escolas isoladas, tais como a Escola Politécnica e a Escola Normal Superior, exteriores à Universidade, que tinham por objetivo atender às exigências da revolução industrial e às demandas por quadros dirigentes para a burocracia estatal. Cabanis confirma assim seu protagonismo num processo histórico rápido, contudo sinuoso e complexo, de criação de um sistema institucional de instrução pública pertinente à nova ordem econômica, social e política instaurada pela revolução burguesa na França. 


\section{Comentários finais}

Influenciado pelos iluministas Diderot, Condillac e Helvétius, Cabanis mostrou-se um fiel apologista da analítica cartesiana, conforme demonstram Staum ${ }^{14} \mathrm{e}$ Williams ${ }^{23}$. Com esse embasamento filosófico, fundado numa perspectiva disciplinar da ciência, defendeu uma revolução da prática médica, em paralelo a um ambicioso programa de reforma do ensino em saúde. No plano político-institucional, a diversidade disciplinar se manifestaria em organismos autocontidos: no campo científico, academias e institutos; no campo educacional, faculdades e escolas superiores. Numa dupla perspectiva de mudança social e educacional, a Reforma Cabanis contribuiu para a extensão desse modo sistemático de organização do conhecimento científico e da formação/reprodução de quadros a outros campos de saberes e práticas. No ensino médico, propiciou a instituição de um regime linear de formação em que o conhecimento se transmite em unidades pedagógicas chamadas de "matérias", e posteriormente de disciplinas, organizadas de modo sucessivo e gradual, do simples ao complexo, do básico ao aplicado, do teórico ao prático, do geral ao específico.

Nesse contexto, com as reformas sociais bonapartistas, consolidou-se uma educação superior regida pelas profissões de saúde legitimadas pelo Estado pós-aristocrático 25,26. Em 12 anos, com avanços e recuos, mudanças profundas foram introduzidas na medicina francesa, culminando com a segmentação e elitização da prática médica mediante a obrigatoriedade da certificação profissional com diploma outorgado por faculdades credenciadas. Esse momento histórico crucial (circa 1800) permitiu a consolidação de um novo modelo de corporações médicas organicamente articuladas com a rede institucional republicana, resultando em um mandarinato 26 meritocrático promovido por um processo político no qual o próprio Cabanis se confirmou como liderança ativa e precoce.

A Reforma Cabanis significou uma resposta à crise de identidade histórica da instituição universitária 27 , todavia transformou essa instituição secular num organismo meramente coordenador de entes independentes: as faculdades. Em paralelo, a Reforma Humboldt fomentou a implantação da chamada universidade de pesquisa como gerador de desenvolvimento econômico e cultural da Alemanha e, posteriormente, dos países anglo-saxões. Desde então, os países industrializados paulatinamente abandonaram o modelo original da educação superior de recorte cabanisiano. Assim, em função de uma série de eventos encadeados, já no século XX, inicialmente a Reforma Flexner e recentemente o Processo de Bolonha, as universidades do Norte Global e suas ramificações cada vez mais evoluem para arquiteturas curriculares baseadas em educação geral, com foco na pesquisa e organizadas em ciclos de formação 27.

Não obstante, o sistema francês de ensino serviu de exemplo para outros povos submetidos à poderosa influência ideológica e cultural da França, particularmente na Europa meridional e nos países recém-saídos da condição de colônia. Com base nessa matriz ideológica, a partir de 1835, implantam-se faculdades de medicina no Rio de Janeiro e na Bahia, seguidas pelas faculdades de direito de São Paulo e do Recife, juntamente com escolas politécnicas e escolas de minas 11. Desse modo, em meados do século XIX, consolida-se no Brasil o império das faculdades, um modelo de educação superior em que as universidades têm papel secundário na formação profissional.

Considerando as bases históricas acima expostas, pode-se enfim formular de modo mais preciso a hipótese objeto deste ensaio: a educação superior brasileira exibe um curioso traço arqueológico, pois, de modo hegemônico, conserva o regime institucional de faculdades e cultiva o conceito nominal de universidade, com entrada de estudantes diretamente em cursos de graduação profissional fundados sobre estruturas curriculares tendencialmente fixas, organizadas por blocos de conteúdos denominados matérias ou disciplinas, ainda dentro do modelo institucional e político-pedagógico estabelecido na Reforma Cabanis.

$\mathrm{Na}$ área da Saúde, essa hipótese pode ser empiricamente testada com a avaliação comparativa da estrutura dos currículos e dos modelos de ensino-aprendizagem praticados nas escolas médicas brasileiras. O objetivo de tal pesquisa será recolher, nos programas curriculares de formação profissional em saúde, indícios, resíduos e traços identificadores do modelo cabanisiano, assim reconhecido: ensino estruturado em cursos lineares, ministrados por faculdades, com currículos fechados, modelados para memorização, baseados em disciplinas (ou matérias), operando modelos de pedagogia analítica para graduar especialistas legitimados por diplomas licenciadores de profissões ditas imperiais, reminiscência do modelo vocacional bonapartista que influenciou, de modo indelével, a organização do campo da educação nos países mediterrâneos e suas ex-colônias 28 . 
Por ironia histórica, o Brasil de início do século XXI, corre o risco de se tornar o "último bastião" do modelo de ensino que, no início do século XIX, o revolucionário Cabanis inspirou ao reformador Bonaparte e que, duzentos anos depois, até mesmo a nação francesa que o originou busca hoje superá-lo.

\section{Agradecimentos}

Denise Coutinho, do Instituto de Psicologia da Universidade Federal da Bahia, revisou conteúdo e escrita, e contribuiu com rico diálogo sobre conceitos básicos deste ensaio. Ao Conselho Nacional de Desenvolvimento Científico e Tecnológico pela Bolsa de Produtividade em Pesquisa nível 1-A (processo: 306341/2011-5).

\section{Referências}

1. Almeida-Filho N. Reconhecer Flexner: inquérito sobre produção de mitos na educação médica no Brasil contemporâneo. Cad Saúde Pública 2010; 26:2234-49.

2. Almeida-Filho N. Nunca fomos Flexnerianos: Anísio Teixeira e a educação superior em saúde no Brasil. Cad Saúde Pública 2014; 30:2531-53.

3. Foucault M. O nascimento da clínica. Rio de Janeiro: Forense Universitária; 2011.

4. Flexner A. Medical education in the United States and Canada. New York: Carnegie Foundation for the Advancement of Science; 1910.

5. Almeida-Filho N. Higher education and health care in Brazil. Lancet 2011; 377:1898-900.

6. Crosland M. The officiers de santé of the French Revolution: a case study in the changing language of medicine. Med Hist 2004; 48:229-44.

7. Charle C, Verge J. História das universidades. São Paulo: Editora Unesp; 1996.

8. Cunha LA. A universidade temporã: o ensino superior da colônia à era Vargas. São Paulo: Editora Unesp; 2007.

9. Tosi L. Ciência e a mulher. Ciênc Hoje 1991; 13:26.

10. Freire-Costa J. A face e o verso. Estudos sobre o homoerotismo II. São Paulo: Escuta; 1995.

11. Caponi S. Clima, cerebro y degeneración em Cabanis. Hist Ciênc Saúde-Manguinhos 2009; 16:961-79.

12. Santos-Sousa RA. A extinção dos brasileiros segundo o conde Gobineau. Revista Brasileira de História da Ciência 2013; 6:21-34.

13. Picavet F. Les idéologues. Essai sur l'histoire des idées et des théories scientifiques, philosophiques, religieuses, etc. en France depuis 1789. New York: Burt Franklin; 1971.

14. Staum M. Cabanis: enlightenment and medical philosophy in the French Revolution. Princeton: Princeton University Press; 1980.

15. Role A, Boullet L. Georges Cabanis, médecin de Brumaire. Paris: Éditions Fernand Lanore; 1994.

16. Gourdol JY. Pierre-Jean-Georges Cabanis (1757-1808), médecin, philosophe et homme politique français. Paris: Medarus; 2010.

17. Mrozovski R. Médecine et politique dans l'œuvre de Pierre-Jean-Georges Cabanis [Tese de Doutorado]. Paris: Université Paris 1 - Panthéon-Sorbonne; 2013.

18. Pouliquen Y. Cabanis, um idéologue de Mirabeau à Bonaparte. Paris: Odile Jacob; 2013.

19. Cabanis PJG. Sur un mode provisoire de police médicale. Paris: [publisher unknown]; 1798. http://www.academie-francaise.fr. 
20. Cabanis PJG. Coup d'oeil sur les révolutions et la réforme de la médecine. Paris: [publisher unknown]; 1804. http://www.academie-fran caise.fr.

21. McGinnis J. Avicenna. Oxford: Oxford University Press; 2010.

22. Anstey P. The creation of the English Hippocrates. Med Hist 2011; 55:457-78.

23. Williams E. The physical and the moral: anthropology, physiology, and philosophical medicine in France, 1750-1850. Cambridge: Cambridge University Press; 1994.

24. Clavreuil J. A ordem médica. Poder e impotência do discurso médico. São Paulo: Brasiliense; 1983.

\section{Abstract}

Georges Cabanis was a reformer of clinical practice and medical education who laid the conceptual foundations during the French Revolution for the development of education in France over the course of the 19th century. The model, in turn, marked the organization of educational systems in many Latin American countries. The objective of this article is to present and justify a hypothesis: the model of medical education still hegemonic in Brazil is still based upon the Cabanisian reform, holding a linear and Cartesian conceptual perspective, with a discipline-based curriculum, traditional teaching formats, and submission to corporate professional logic. In order to better understand the social and political context of the historical processes that generated this anachronism, I begin with a summary of the biography and thinking of Georges Cabanis, introducing him as a central character in his historical context. Next, I highlight the main structural elements in the Cabanis model, with a special focus on medical teaching, drawing on some of his writings as the documental source. Finally, in broad strokes, I present the project for reform of medical teaching elaborated by Cabanis and his collaborators as backing for a preliminary evaluation of the proposed hypothesis.

Health Education; Teaching; Universities; History of Medicine
25. Weisz G. The emergence of medical specialization in the nineteenth century. Bull Hist Med 2003; 77:536-75.

26. Weisz G. The medical mandarins: the French Academy of Medicine in the nineteenth and early twentieth centuries. Oxford: Oxford University Press; 1995.

27. Seabra-Santos F, Almeida-Filho N. A quarta missão da universidade: internacionalização universitária na sociedade do conhecimento. Coimbra: Imprensa da Universidade de Coimbra/Brasília: Editora UnB; 2012.

28. Coelho EC. As profissões imperiais: medicina, engenharia e advocacia no Rio de Janeiro, 18221930. Rio de Janeiro: Editora Record; 1999.

\section{Resumen}

Georges Cabanis fue un reformista de la práctica clinica y enseñanza médica que, durante la Revolución Francesa, lanzó las bases conceptuales del modelo de educación implantado en Francia a lo largo del siglo XIX. Ese modelo, a su vez, marcó la organización de los sistemas educacionales de muchos países latinoamericanos. El objetivo de este artículo es presentar y justificar una hipótesis: el modelo de educación médica hegemónico en Brasil, todavía hoy en día, se basa en la reforma cabanisiana, desde una perspectiva conceptual lineal y cartesiana, con una matriz curricular disciplinaria, formatos tradicionales de práctica pedagógica y sumisión a la lógica profesional corporativa. Para una mejor comprensión del contexto social $y$ político de los procesos históricos generadores de este anacronismo, en primer lugar, expongo un resumen de la biografía y del conjunto del pensamiento-obra de Georges Cabanis, presentándolo como un personaje central en su contexto histórico. En segundo lugar, destaco los principales elementos estructurales del modelo cabanisiano, centrándome especialmente en la enseñanza médica, tomando algunos de los textos de su autoría como fuente documental. Finalmente, de forma sucinta, presento el proyecto de reforma de la enseñanza médica, elaborado por Cabanis y sus colaboradores, como apoyo para la evaluación preliminar de la hipótesis propuesta.

Educación en Salud; Enseñanza; Universidades; Historia de la Medicina

Recebido em 20/Dez/2016

Versão final reapresentada em 25/Mai/2017

Aprovado em 13/Jun/2017 